\title{
The Supply of Cellular Energy by Changing in Diet and Life-Style a Possible Treatment for Uterine Myoma and Cyst: A Case Report
}

\author{
Hassan Akbari ${ }^{1,2}$, Khadije Heydarolad $^{3^{*}}$
}

\author{
ISchool of Persian Medicine, Tehran University of Medical Sciences, Tehran, Iran. \\ 2Department of Pathology, Shahid Beheshti University of Medical Science, Tehran, Iran. \\ ${ }^{3}$ Iranian Traditional Medicine Doctor, University of Traditional Medicine of Armenia, UTMA. \\ *Correspondence to: Khadije Heydarolad (E-mail: hassanakbariz3@yahoo.com) \\ (Submitted: 17 April 2021 - Revised version received:29 April 2021 - Accepted:23 May 2021 - Published online: 26 August 2021)
}

\begin{abstract}
Objectives Uterine myoma and cervical cyst are common benign tumors. If the size is too large or the symptoms are severe or get worse, the patient will receive surgery or hormone therapy. A 68 years old woman presented to a hospital in Iran with abnormal uterine bleeding (AUB). After performing sonography and suitable imaging, the patient was diagnosed with cervical cyst and uterine myoma. The patient was candidate for hysterectomy. The patient was not willing to do surgery. We tried a traditional medicine approach for this case. We recommended the lifestyle change by following the health triangle instruction that is based on six essential principles. These principles are as following: eating and drinking according to temperament, proper sleeping and awaking, correct motion and motionless, retention and vomiting, mental disorders. She received traditional medicine treatment including dietary and life-style change, using vaginal honey and olive oil, Frasion sodden, Aftimoni honey vinegar, Docein, horsehair sodden and phlebotomy, wet cupping and dry cupping on specific regions. The treatment course was 4 months long. The complete cure of cervical cyst and reduction in size of myoma and bleeding was resulted. And the patient had no problem.
\end{abstract}

Keywords Uterine myoma, cervical cyst, traditional medicine, health triangle

\section{Introduction}

The uterine myoma or fibroids with or without cyst is the most common benign tumor of the female reproductive system causing significant morbidity and impairing their quality of life. It is frequently found in fertile women aged 16 to 50 years old. The etiology of the disease is not clearly known. Gene abnormality and hormonal effects are associated with the disease. ${ }^{1}$ While many cases remain asymptomatic, myomas may presents with abnormal uterine bleeding, pelvic pain, sciatica, urinary frequency, dysuria, constipation, infertility, and, in extreme cases, ureteral obstruction and death according to the site, type, and size of the lesion. ${ }^{2}$

Todays, surgery (hysterectomy) is the most attempted treatment in cases with large tumor size or severe symptoms. Myomas are the underlying cause of half all performed hysterectomies. Removal of the uterus is inacceptable to many women whether they are willing to bearing a child later or simply because of psychological burden. Besides, surgical interventions carry lots of possible complications, including bleeding, injury to bladder, intestine or ureters, subsequent adhesion formation and obstruction, complications of anesthesia and of hospitalization in general. Also, surgeries impose many costs to the patients and health systems. ${ }^{3}$ All of these consequences lead the current treatment approaches to non-surgical and conservative ones and over the years conservative approaches have been introduced. Changing in cellular energy can cause numerous diseases including myomas and cysts. Supplying cellular energy by changing in nutrition and life style could be a possible treatment for myomas and cysts.

In this case report we treated a 48-year-old woman who was diagnosed with uterine myoma and cervical cyst by changing pattern of nutrition and lifestyle and using some traditional Persian medicine approaches from September 2020 to December 2020. She was candidate for hysterectomy.
However, she was not willing to receive any surgical intervention or hormone therapy.

\section{Case Description}

\section{Patient Characteristics and Medical History}

A 48-year-old woman without any past medical history referred to Baqiatallah hospital, Tehran, Iran in September 2020 with the chief complaint of excessive bleeding during menstruation from one year ago. Other complaints were 1) feeling a pressure in hypo-gastric area which begins $2-3$ days before the menstruation and lasts for 1-2 days after menstruation 2) dysmenorrhea, from one year ago menstrual pain worsened and the volume of bleeding increased so she took painkillers on the first day of menstruation. She had not any complaint of dysuria, frequency in urination and Leucorrhea.

Her menstrual cycle was 25-28 days long and regular and her menstruation duration was 7 days. She had a obstetric history of three full-term births, pre-term birth 0 , abortion 0 and live offspring 3 (GPAL: 3-0-0-3).

Physical examinations of the patient were as follows: 1) General appearance: pale, 2) pulse: weak, thin and symmetric, 3) sleep: normal, 4) defecation: normal, 5) urination: normal, 6) abdomen: a mass was palpable in the hypo gastric area without tenderness, 7) vaginal examination with speculum: no abnormal secretion or bleeding was observed, a $2 \mathrm{~cm}$ cyst was observed on the cervix, 8) anthropometrics: $160 \mathrm{~cm}, 61.7 \mathrm{~kg}$, BMI: 24.1. After examination and taking history the patient temperament was diagnosed as a cold-wet type.

The gynecologist requested ultrasound of uterus and ovaries and appendages. A $22 \mathrm{~mm}$ myoma was observed in the anterior septum of the uterine and along with a $15 \mathrm{~mm}$ cyst in 
the cervical area. The patient was candidate for hysterectomy by the gynecologist physician. The patient was not willing to do the surgery because of psychological burden. She visited the traditional medicine clinic seeking the non-surgical treatment.

\section{Treatment and Progress of Symptoms}

\section{Therapeutic Map}

We recommended the patient to change the lifestyle by following the health triangle instruction that is based on four essential principles, including eating and drinking a wellbalanced diet and according to temperament, proper sleeping and awaking (getting at least 8 hours of sleep every night) and physical activity.

\section{Dietary Intervention}

The recommended dietary changes according to temperament were as follows: 1 ) replacing the current consumable oils with consumed sesame, olive and animal oil, 2) replacing the iodized salt with natural organic salt, 3) not using the white sugar, cub sugar, tomatoes and tomatoes sauce.

\section{Pharmaceutical Intervention}

The ordered pharmaceutical interventions were as follows: 1) using vaginal honey and olive oil one other night, for 7 session a week, to healing only vaginal honey and olive oil, 2) daily drinking of glass of Frasion sodden with honey, for four months, 3 ) drinking one glass of Aftimoni honey vinegar daily (one third of the glass should be honey vinegar, and the rest should be water) for two month, and then typical honey vinegar for 40 days, 4) consuming Docein every 12 hours one tablespoon up to 2 months, 5) Using horsehair sodden to stop bleeding, 2 glass daily, 6) consuming bark pomegranate pollen a tablespoon every 8 hours.

\section{Manual Practices}

For the perfect result we also carry out right hand phlebotomy, then after a month we performed wet cupping between the two shoulders, and after two weeks we performed sacral cupping, waist and hypogastria warm and dry cupping for 21 sessions by chamomile oil.

\section{Progress of the Symptoms}

The main symptoms of the patient were resolved after the treatments and the hysterectomy was not accomplished. The excessive bleeding which the patient was complaining about was reduced to the normal amount. And the patient did not report any side effects during the course of treatment. In the follow up solography it was specified that the $15 \mathrm{~mm}$ cervical cyst was completely vanished and the myoma size reduced to $17 \mathrm{~mm}$. the following months the patient had not any problem.

\section{Informed Consent and Ethics}

For using of personal medical information for publication the informed consent was obtained from the patient.

\section{Discussion}

In this case study, traditional Persian medicine was found to be effective for women with uterine myoma and cervical cyst who did not want surgical interventions or hormone therapy.
Patients may refuse surgical interventions because of fear of surgery, financial and psychological burdens or individual situation. These patients could be alternatively treated with conservative and traditional medicine instead of invasive surgery. For this purpose, we should provide enough information on the advantages and disadvantages of various treatments.

Uterine myoma (fibroids) can form in reproductive organs of women especially in ages of 16 to 50 . The genetic and environmental factors have both associated with this disease. The environmental factors that affect health could be perfect targets to treat and prevent myomas. One of these factors is undoubtedly life-style and diet. Studies support the idea that regular intake of fruits and cultured milk food, availability of quality preferences in diet, regular exercises, frequent foot walks at clean air could prevent the formation of uterine myoma. ${ }^{4}$ Besides, cellular energy deprivation could lead to many diseases and lesions including uterine cysts and myomas. If the energy is not sufficient, the immune system and mechanism that destroy the pathologies in the body are the firsts that damage. ${ }^{5}$ By improving the cellular energy and supplying this energy deficiency for immune system cells, smooth muscle cells of uterine myomas and epithelial cells of cysts, the body as a complex system can automatically eliminate the pathologic cells. The underlying mechanism includes pathologic cells apoptosis with the aim of macrophages and other immune system cells. ${ }^{6}$ In addition, some specific temperament are associated with gynecological diseases. ${ }^{7}$ These results highlight the importance of balanced diet which is in accordance with temperament on preventing and improving the uterine myoma. The main component of our therapeutic approach was honey. There are several studies on the anti-tumor effect of honey. ${ }^{8}$ The possible mechanisms for anti-tumor activity of honey and its ingredients are antioxidant, anti-inflammatory, ant proliferative, apoptotic, tumor necrosis factor inhibiting, immune modulatory and estrogenic effects. ${ }^{9}$ Honey along with bark pomegranate pollen have benefits that we found is suitable for preventing and improving uterine myoma, including anti-oxidant and anti-tumor compounds in pomegranate and honey. The pharmaceutical therapy has also the effect of relieving blood clots and improving dysmenorrhea by promoting blood circulation. ${ }^{10,11}$ Along with pharmaceutical therapies and life-style change traditional medicine manual practices have also been found to be effective in numerous diseases. ${ }^{12}$ A case report of the effectiveness of dry cupping on uterine fibroid has been recently published..$^{13}$ According to the Traditional Persian medicine, cupping therapy has a favorable effect on uterus and ovaries functions improvement and is recommended for their related diseases. ${ }^{14}$

The possible therapeutic effects of cupping therapy have been studied previously. Cupping therapy increases opioid production in body which can induce comfort, muscle relaxation and pain reduction. It has also increases blood flow to the muscles and skin, stimulates the peripheral and autonomic nervous systems, and modulates the immune system and hormonal balance. ${ }^{15}$ It is shown that dry cupping can decrease pain intensity and menstrual bleeding. Cupping can also divert blood flow away from the pelvic area and reduce the congestion in female reproductive system and finally reducing pain and tumor size. ${ }^{16}$ 


\section{Conclusion}

In conclusion, supplying the cellular energy deprivation of the immune system cells and smooth muscle cells of myomas and epithelial cells of cysts by changing in nutrition and lifestyle could be an alternative therapy for uterine myomas and cysts for patients who are unwilling to receive hormonal therapy and perform surgeries.

\section{References}

1. Sparic R, Mirkovic L, Malvasi A, Tinelli A. Epidemiology of Uterine Myomas: A Review. Int J Fertil Steril. 2016;9(4):424-35.

2. El-Balat A, DeWilde RL, Schmeil I, Tahmasbi-Rad M, Bogdanyova S, Fathi A, et al. Modern Myoma Treatment in the Last 20 Years: A Review of the Literature. BioMed Research International. 2018;2018:4593875.

3. Okolo S. Incidence, aetiology and epidemiology of uterine fibroids. Best practice \& research Clinical obstetrics \& gynaecology. 2008;22(4):571-88.

4. Feofilova MA, Pavlov OG, Geimerling VE. [The Effect of Life-Style and Occupational Hazards on Development of Hysteromyoma]. Probl Sotsialnoi Gig Zdravookhranenniiai Istor Med. 2018;26(6):406-10.

5. Delmastro-Greenwood MM, Piganelli JD. Changing the energy of an immune response. Am J Clin Exp Immunol. 2013;2(1):30-54.

6. Gerkau NJ, Rakers C, Petzold GC, Rose CR. Differential effects of energy deprivation on intracellular sodium homeostasis in neurons and astrocytes. J Neurosci Res. 2017;95(11):2275-85.

7. Sahebi L. The Association between Temperament and Gynecological Disease from Persian Medicine Point of View. 2020.

8. Cianciosi D, Forbes-Hernández TY, Afrin S, Gasparrini M, ReboredoRodriguez P, Manna PP, et al. Phenolic Compounds in Honey and Their Associated Health Benefits: A Review. Molecules. 2018;23(9).

9. Waheed M, Hussain MB, Javed A, Mushtaq Z, Hassan S, Shariati MA, et al. Honey and cancer: A mechanistic review. Clin Nutr. 2019;38(6):2499-503.

10. Pyo SJ, Kang DG, Jung C, Sohn HY. Anti-Thrombotic, Anti-Oxidant and Haemolysis Activities of Six Edible Insect Species. Foods. 2020;9(4).

11. Kandylis P, Kokkinomagoulos E. Food Applications and Potential Health Benefits of Pomegranate and its Derivatives. Foods. 2020;9(2).

12. Cao H, Li X, Liu J. An updated review of the efficacy of cupping therapy. PloS one. 2012;7(2):e31793.

13. Majid D, Mohamad Hossein A, Sara R, Elham A. Effectiveness of Dry Cupping Therapy in the Management of Uterine Fibroid: A Case Report. Traditional and Integrative Medicine. 2020;5(2).

14. Mokaberinejad R, Rampisheh Z, Aliasl J, Akhtari E. The comparison of fennel infusion plus dry cupping versus metformin in management of oligomenorrhoea in patients with polycystic ovary syndrome: a randomised clinical trial. J Obstet Gynaecol. 2019;39(5):652-8.

15. Al-Bedah AMN, Elsubai IS, Qureshi NA, Aboushanab TS, Ali GIM, El-Olemy AT, et al. The medical perspective of cupping therapy: Effects and mechanisms of action. J Tradit Complement Med. 2018;9(2):90-7.

16. Inanmdar W, Sultana A, Mubeen U, Rahman K. Clinical efficacy of Trigonella foenum graecum (Fenugreek) and dry cupping therapy on intensity of pain in patients with primary dysmenorrhea. Chin J Integr Med. 2016.

This work is licensed under a Creative Commons Attribution-NonCommercial 3.0 Unported License which allows users to read, copy, distribute and make derivative works for non-commercial purposes from the material, as long as the author of the original work is cited properly. 